\title{
Diagnosing soft tissue sub-surface masses using the XCS classification system
}

\author{
Navid Moshtaghi Yazdani ${ }^{*}$ (iD) \\ ${ }^{1}$ Department of Electrical Engineering, Mashhad Branch, Islamic Azad University, Mashhad, Iran
}

\begin{tabular}{ll}
\hline Article Info & A B S T R A C T \\
\hline $\begin{array}{l}\text { Article type: } \\
\text { Research }\end{array}$ & Introduction: One of the most common types of cancer is breast cancer, \\
& which is considered as the second leading cause of death in women in Iran. \\
& Due to the fatality of this type of cancer, it is very important to diagnose the \\
disease in the early stages and starting the treatment process. One of the & methods to diagnose breast cancer is using mechanical arms (robot \\
Article History: & manipulator) to touch and measure the force in terms of displacement at the \\
Accepted: $2020-10-16$ & site of the breast touch by the robot. The hardness of the cancer tissue can \\
Published: $2020-11-02$ & affect the force diagram in terms of displacement, which can be used as a \\
& diagnostic method. The present study was performed to prepare a \\
* Corresponding author: & simulation model of breast soft tissue behavior considering subsurface \\
Navid Moshtaghi Yazdani & masses. Then, a proposed classification system was designed to fit it.
\end{tabular}

Departmentof Electrical

Engineering, Mashhad Branch,

Islamic Azad University,

Mashhad, Iran

Email: navid.moshtaghi@ut.ac.ir
Material and Methods: In this section, first, the soft tissue behavior of the breast is simulated by considering sub-surface masses. The simulations are performed for a piece of tissue that is in the shape of a rectangular cube, as well as different dimensions of a spherical mass that is located at different depths and coordinates. Using simulation, various force-displacement diagrams have been obtained, based on which a data network.

Results: The displacement force diagram for different modes is obtained using simulation. By giving the resulting diagrams to the trained system, the size and depth of the mass is determined. By comparing the obtained results with the initial model and the actual size and depth of the mass, a very good conformity is observed, which indicates the correct operation of the designed system and the performed simulation process.

Conclusion: The proposed design system was used to diagnose the presence of tumors in tissue with sub-surface mass. The results show a high percentage of this method in diagnosis. However, the accuracy of this method can be greatly increased by increasing the amount of data given to the XCS system for training. On the other hand, instead of simulation data, test data on healthy and unhealthy people can be used for training.

\section{Cite this paper as:}

Moshtaghi Yazdani N. Diagnosing Soft Tissue Sub-Surface Masses Using the XCS Classification System. Front Health Inform. 2020; 9: 49. DOI: $10.30699 /$ fhi.v9i1.239

\section{INTRODUCTION}

One of the most common types of cancer is breast cancer, which is considered as the second leading cause of death in women in Iran. Due to the fatality of this type of cancer, it is very important to diagnose the disease in the early stages and starting the treatment process [1].

Common methods of studying the behavior of this tissue in medicine are manual touch, ultrasonic waves (sonography) and electromagnetic waves (mammography). Manual touch is usually done using experienced force, which is associated with human error. Diagnostic mammogram is actually a radiograph, X-ray of the chest which due to the consequences of using X-rays on the body, this method is considered in the group of harmful and invasive methods to the body []].

Sonography is a non-invasive method that is used to evaluate dense breasts. In this method, the results may be too positive to recognize even normal tissue as a tumor. Ultrasound imaging has so far been proposed as a complementary method of treatment, so that the use of this method alone is not standard for the diagnosis of cancer [ $\underline{3}]$. 
Researches that have been committed by researchers clearly shows that the stiffness of cancer masses is much more than the stiffness of healthy breast tissue [4]. The same difference in stiffness of the tissue is the main basis for identifying cancer appendages in the breast using its clinical examination.

This behavior has led researchers to focus on building a device that uses tactile sensors and touch the patient's breast tissue to quantify its stiffness and use the results to identify cancer masses. Although this method has been used to identify and treat some other diseases $[\underline{5}, \underline{6}]$, but its main application is in identifying breast cancer masses. In many early studies conducted by researchers, measuring the modulus of elasticity of breast tissue and analyzing its changes is the basis for identifying cancer masses. In this research, by applying force at two different levels and measuring the deformation created in the tissue, the modulus of elasticity of the tissue was calculated. In other studies, the distribution of stress on the surface of the breast in the force exerted on it has been measured and used to calculate the firmness of the tissue [7].

Majra et al. also designed a robot that intelligently touches the patient's breast, and by analyzing the stress created in it, diagnoses cancer masses [ㅁ-10]. Based on the obtained results, using tactile diagnosis methods and diagnosis of breast cancer using tactile sensors can be an affordable method and relatively accurate for periodic monitoring of women [11].

One of the diagnostic methods is using a force sensor that is placed on the tissue and penetrates into it, the sensor records the force diagram in terms of penetration depth at the measuring point. According to the diagrams recorded in different parts of the breast tissue, its size and depth can be diagnosed due to the different severity of the cancerous mass. Accordingly, in this paper, despite a sub-surface mass, the penetration of a spherical probe (mandrel) into the breast tissue is simulated.

The breast tissue was considered to be a rectangular cube with a certain depth. The penetration of the probe in different parts of the breast tissue is simulated in Abacus software, based on which the force diagram is obtained in terms of the location of the probe for different features and sizes of the tumor. Then, using the results, a classification system is trained to diagnose the size and depth of the tumor. Finally, using multiple simulations, the correct performance of the proposed system is checked. Some of the simulation results are given as input to the system and others are used to validate the performance.

\section{MATERIAL AND METHODS}

According to the disadvantages mentioned in different methods of diagnosing breast tumor and modeling the tactile sense, a device has been designed to diagnose the presence of breast masses. This device (tactile gland finder) consists of the following 4 parts: 1) Pressure or force sensor; 2) explorer as the part on which the sensor will be installed (manipulator part); 3) Electrical circuit and information processing center; and 4) A monitor to show changes in pressure or force perceived by the sensor.

The basis of this device is to measure the pressure or contact force between the sensor and the tissue. The method of examination is that the user takes the explorer device and places it on the body so that the sensor makes contact with the body surface; and the amount of pressure will be recorded by the force exerted on the sensor by the body surface; the user then moves the explorer device from the previous location to the new location and does so at several points in the desired texture [9], but using this device itself requires simulating behavior of the loaded texture. In this article, breast tissue is assumed to be a cube with specific depth and dimensions, which includes three layers that is skin, fat and main tissue.

Also, a tumor with a certain depth and location is located inside the tissue. To diagnose the location and size of the tumor, the proposed XCS classification system in [12] is used, which has a very high accuracy. Using the simulation results for multiple samples, the system is trained in such a way that force diagrams in terms of displacement are used as input and the location and size of the simulated tumor are also used as output. The force diagram is then entered as input to the trained system in terms of the displacement of a number of simulations, and the output of the system, which is an estimate of the coordinates and size of the tumor, is taken. Using the obtained results, it is possible to check the correct operation of the designed system.

\section{RESULTS}

\section{Software requirements}

The simulated geometry consists of three rectangular layers with dimensions of $80 \times 100$ and thickness of 44, 6 and $2 \mathrm{~mm}$ for the main texture, fat and skin, respectively (Fig 1). The tumor is also modeled as a sphere with variable diameter. The mandrel or submersible object was also considered as a sphere with a diameter of $5 \mathrm{~mm}$. Due to symmetry, the problem can be solved partially. Each one of mentioned layers and the tumor have their own properties that have been used from the references. The properties of each layer is a function of the amount of its deformation that is entered in ABAQUS software according to Table 1 . Due to the incompressibility of body tissues, the Poisson coefficient for all three layers is considered 0.6 , which is close to the reality. 


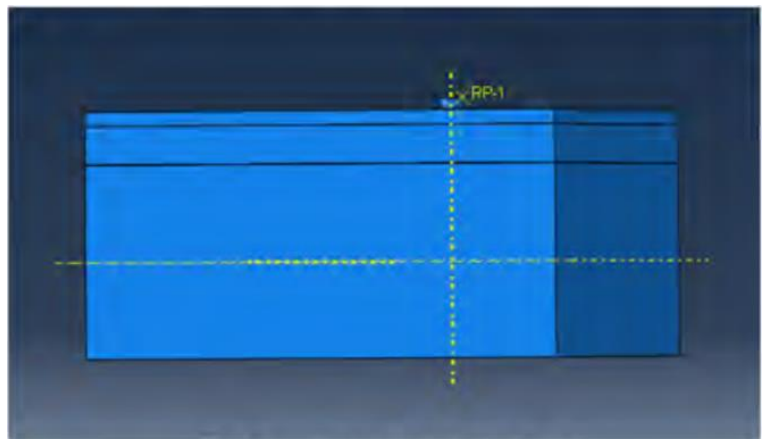

Fig 1: Simulated model in ABAQUES software

Table 1: Mean modulus of elasticity for each of the different parts of the chest at different strains [11]

\begin{tabular}{|l|c|c|c|c|}
\hline \multirow{2}{*}{$\begin{array}{l}\text { Type of } \\
\text { tissue }\end{array}$} & \multicolumn{4}{|c|}{ Modulus of elasticity } \\
\cline { 2 - 5 } & \multicolumn{4}{|c|}{ Amount of strains } \\
\cline { 2 - 5 } & 0.01 & 0.05 & 0.1 & 0.15 \\
\hline Fat & 4.8 & 6.6 & 10.4 & 17.4 \\
\hline $\begin{array}{l}\text { Main } \\
\text { tissue }\end{array}$ & 17.5 & 33 & 88.1 & 271.7 \\
\hline Tumor & 57.8 & 90.8 & 164.3 & 297.7 \\
\hline
\end{tabular}

The behavior of the layers is modeled using the hyper-elastic model and based on the results of simple tension based on the results of the uniaxial tension test of Table 1 . To simulate the layers, due to their complete connection in reality, the Tie model (glue) has been used in Abacus software. The vertical displacement of the mandrel and its penetration depth in the breast tissue is assumed to be $8 \mathrm{~mm}$. In the next step, the model is meshed using a quadrilateral element.

After simulating the force diagram in terms of mandrel displacement for the studied problem is obtained for tumors with different location, depth and size. Fig 2 shows an example of the simulations performed in which the stress contour was displayed.

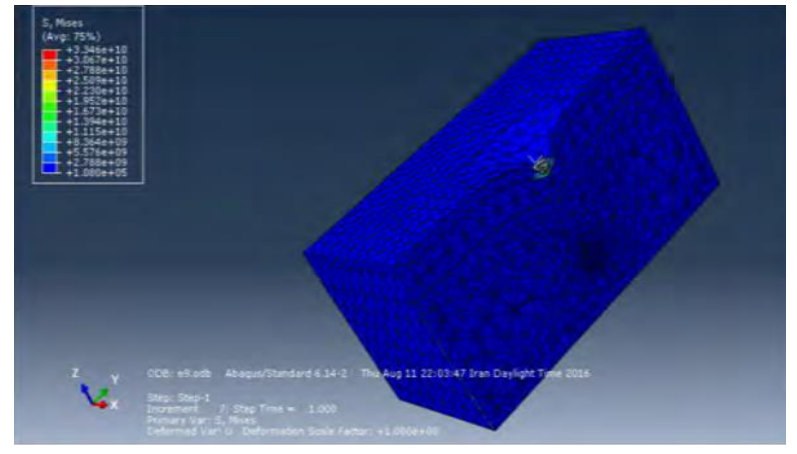

Fig 2: View of the application of force to the simulated tissue

As mentioned, to train the designed system, multiple simulations need to be performed for different locations, sizes, and depths of the tumor. For this purpose, simulations were performed for 8 different locations on the $\mathrm{x}-\mathrm{y}$ plane shown in Fig 2 and for three different depths for tumors and have been performed for tumors with diameters of 3,7 and $10 \mathrm{~mm}$. Therefore, 512 simulations have been performed, which for each case, the force diagram in terms of displacement in 9 points was shown in Fig 3 is also calculated to be used in the next step to train the designed system.
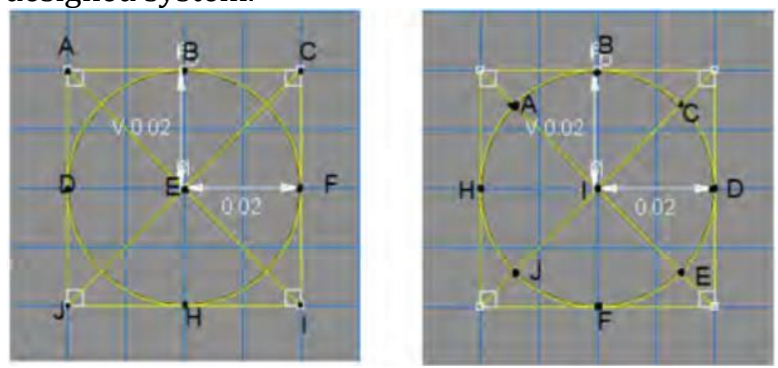

Fig 3: Location of force measurement in terms of displacement

\section{Diagrams}

The simulations can be used to train and use a designed system to diagnose the location and size of the tumor. Therefore, the simulation results are divided into two parts. The first part contains the results of 400 simulations used for training and the next part which contains the results of the remaining 112 simulations used to validate the designed system. For this purpose, for the first 75 cases, the measurement location and the data obtained from the force diagram in terms of the displacement of the mandrel are considered as input, and the size and coordinates of the tumor are considered as output. 112 remained cases include entered force for a displacement of $1 \mathrm{~cm}$ at the 9 points is shown in Fig 3. After training, it can be validated using 112 data series. In this series of data, the force diagram is given as input to the system according to the displacement of the mandrel obtained from the simulation, and the trained system obtains the size and coordinates of the tumor.

The results of the designed system for 112 cases obtained to validate the function of the system designed to diagnose the location and size of the tumor are shown in Table 2. Table 3 also shows the difference between the values calculated by the designed system and the actual values. In these tables, $\mathrm{X}, \mathrm{Y}$, and $\mathrm{Z}$ represent the true coordinates of the tumor, respectively, and X ', Y', and Z 'represent the values calculated by the system. As can be seen, there is a good conformity between the results of the designed system and the actual values, which indicates that the system is designed to function, so it is suggested that the method used in this article to detect the presence of tumors in the breast of individuals. Used. 
Table 2: Actual values and results from the XCS classification system to identify the location and size of the tumor

\begin{tabular}{|c|c|c|c|c|c|c|c|c|}
\hline $\begin{array}{l}\pi_{0} \\
\sum^{2}\end{array}$ & $\mathrm{X}$ & $\mathrm{Y}$ & Z & $\mathrm{D}$ & $X^{\prime}$ & $Y^{\prime}$ & $Z^{\prime}$ & $D^{\prime}$ \\
\hline 1 & 0 & 0 & 20 & 5.5 & -0.003 & -0.018 & 20.755 & 4.925 \\
\hline 2 & 12 & 12 & 34 & 10 & 12.588 & 12.361 & 39.652 & 9.020 \\
\hline 3 & 0 & 20 & 31 & 5.5 & 0.052 & 19.319 & 30.500 & 4.569 \\
\hline 4 & -20 & 0 & 31 & 2 & -19.546 & 0.203 & 31.206 & 2.258 \\
\hline 5 & 0 & -20 & 34 & 10 & 0.086 & -19.562 & 33.873 & 9.327 \\
\hline 6 & -15 & -15 & 35 & 5.5 & -14.528 & -14.336 & 34.614 & 5.246 \\
\hline
\end{tabular}

Table 3: The difference between the output of the classification system and the actual values

\begin{tabular}{|l|c|c|c|c|}
\hline Row & $\mathrm{X}^{\prime}-\mathrm{X}$ & $\mathrm{Y}^{\prime}-\mathrm{Y}$ & $\mathrm{Z}^{\prime}-\mathrm{Z}$ & $\mathrm{D}^{\prime}-\mathrm{D}$ \\
\hline 1 & 0.003 & 0.018 & 0.755 & -0.575 \\
\hline 2 & 0.588 & 0.361 & 5.652 & -0.98 \\
\hline 3 & 0.052 & -0.581 & -0.500 & -0.931 \\
\hline 4 & 0.454 & 0.203 & 0.206 & 0.258 \\
\hline 5 & 0.086 & 0.438 & -0.127 & -0.673 \\
\hline 6 & 0.472 & 0.664 & -0.386 & -0.254 \\
\hline
\end{tabular}

\section{CONCLUSION}

In this paper, using a new method to improve the performance and increase the convergence rate of the XCS system using limited training data, the problem of breast cancer diagnosis with the help of this system was discussed. To diagnose cancer tissue hardness, soft tissue behavior. The chest was simulated in Abacus software and for power plots with different dimensions, depths and coordinates in terms of displacement. This successful application raises the hope that using the force sensor located on the tissue can be used to detect this with doctors.

\section{AUTHOR'S CONTRIBUTION}

The author agree on this final form of the manuscript.

\section{CONFLICTS OF INTEREST}

The author declare no conflicts of interest regarding the publication of this study.

\section{FINANCIAL DISCLOSURE}

No financial interests related to the material of this manuscript have been declared.

\section{REFERENCESM}

1. Laxminarayan $R$, Chow J, Shahid-Salles SA. Intervention cost-effectiveness: Overview of main messages. In: Jamison DT, Breman JG, Measham AR, Alleyne G, Claeson M, Evans DB, et al. (eds). Disease control priorities in developing countries. $2^{\text {nd }}$ ed. Oxford University Press; 2006.

2. Mushlin AI, Kouides RW, Shapiro DE. Estimating the accuracy of screening mammography: A metaanalysis. Am J Prev Med. 1998; 14(2): 143-53. PMID: $\quad 9631167 \quad$ DOI: $10.1016 / s 0749-$ 3797(97)00019-6 [PubMed]

3. Huber S, Wagner M, Medl M, Czembirek H. Realtime spatial compound imaging in breast ultra sound. Ultrasound Med Biol. 2002; 28(2): 155-63. PMID: 11937277 DOI: $10.1016 / \mathrm{s} 0301-5629(01) 00490-2$ [PubMed]

4. Harris JR, Lippman ME, Morrow M, Hellman S. Diseases of the breast. Lippincott Raven. 1996.

5. Ayyildiz M, Guclu B, Yildiz M, Basdogan C. A novel tactile sensor for detecting lumps in breast tissue. In: Kappers AML, van Erp JBF, Bergmann Tiest WM, van der Helm FCT (eds). Springer Berlin Heidelberg; 2010.

6. Roham H, Najarian S, Hosseini S, Dargahi J. Design and fabrication of a new tactile probe for measuring the modulus of elasticity of soft tissues. Sensor Review. 2007; 27(4): 317-23.
7. Sarvazyan AP, Skovoroda AR, Pyt'ev YP. Mechanical introscopy: A new modality of medical imaging for detection of breast and prostate cancer. Symposium on Computer Based Medical Systems. IEEE; 1997.

8. Mojra A, Najarian S, Towliat Kashani SM, Panahi F, Yaghmaei M. A novel haptic robotic viscogram for characterizing the viscoelastic behaviour of breast tissue in clinical examinations. Int J Med Robot. 2011; 7(3): 282-92. PMID: 21538774 DOI: 10.1002/rcs.396 [PubMed]

9. Mojra A, Najarian S, Towliat Kashani SM, Panahi F, Tehrani MA. A novel robotic tactile mass detector with application in clinical breast examination. Minim Invasive Ther Allied Technol. 2012; 21(3): 210-21. PMID: $21919810 \quad$ DOI: 10.3109/13645706.2011.602087 [PubMed]

10. Mojra A, Najarian S, Towliat Kashani SM, Panahi F. A novel tactile-guided detection and threedimensional localization of clinically significant breast masses. J Med Eng Technol. 2012; 36(1): 8-16. PMID: 22074118 DOI: 10.3109/03091902.2011.629275 [PubMed]

11. Sarvazyan A, Egorov V, JS Son, Kaufman C. Cost effective screening for breast cancer worldwide: Current state and future directions. Breast Cancer (Auckl). 2008; 1: 91-9. PMID: 19578481 DOI: 10.4137/bcbcr.s774 [PubMed]

12. Shariat Panahi M, Moshtaghi Yazdani N. An improved XCSR classifier system for data mining with limited trainingSamples. Global Journal of Science, Engineering and Technology. 2012; 2; 52-7. 